\title{
Modeling Pollutant Penetration across Building Envelopes
}

\author{
De-Ling LiU ${ }^{1}$ aND WILLIAM W NazARoFF ${ }^{1,2}$ \\ 'Environmental Engineering Program \\ Department of Civil and Environmental Engineering \\ University of California, Berkeley, CA 94720-1710 USA \\ Environmental Energy Technologies Division \\ ${ }^{2}$ Indoor Environment Department \\ Lawrence Berkeley National Laboratory \\ Berkelcy, CA 94720 USA
}

April 2001

The-work-was-\$upported-by the Office of Research and Development- - ffice of Nonproliferation and National Security, U.S. Department of Energy under Contract No. DE-AC03-76SF00098. Additional support was provided by the UC Toxic Substances Research and Training Program. 


\section{DISCLAIMER}

This document was prepared as an account of work sponsored by the Unhed States Government. While this document is believed to contaln correct information, neither the United States Government nor any agency thereof, nor the Regents of the University of Califomia, nor any of their employees, makes any warranty, express or implied, or assumes any legal responsibility for the accuracy, completeness, or usefulness of any infomation, apparatus, product, or process disclosed, or represents that its use would not infringe privately owned rights. Reference herein to any specific commercial product, process, or service by its trade name, trademark, manufacturer, or otherwise, does not necessarily conslitute or imply its endorsement, recommendation, or favoring by the United States Govemment or any agency thereof, or the Regents of the University of Califormia. The views and opinlons of authors expressed herein do not necessarly state or reflect those of the United States Government or any agency thereof or the Regents of the University of California. 


\title{
Modeling Pollutant Penetration across Building Envelopes
}

DE-LING LJU AND WILLIAM W NAZAROFF ${ }^{1,2}$

' Envirommental Engineering Program, Department of Civil and Environmental Engineering, University of Califonia, Berkeley, CA 94720-1710 USA

${ }^{2}$ Indoor Environment Department, Lawrence Bcrkeley National Laboratory, Berkeley, CA 94720 USA

\begin{abstract}
As air infiltrates through unintentional openings in building envelopes, pollutants may interact with adjacent surfaces. Such interactions can atter human exposure to air pollutants of outdoor origin. We present modeling explorations of the proportion of particles and reactive gases (e.g., ozone) that penetrate building envelopes as air enters through cracks and wall cavities. Calculations were performed for jdealized rectangular cracks, assuming regular geometry, smooth inner crack surface and steady airflow. Particles of 0.1-1.0 Hm diameter ase predicted to have the highest penetration efficiency, nearly unity for crack heights of $0.25 \mathrm{~mm}$ or larger, assuming a pressure difference of $4 \mathrm{~Pa}$ or greater and a flow path length of $3 \mathrm{~cm}$ or less. Supermicron and ultrafine particles are significantily removed by means of gravitational settling and Brownian diffusion, respectively. In addition to crack geometry, ozone penetration depends on its reactivity with crack surfaces, as parameterized by the reaction probability. For reaction probabilities less than $\sim 10^{-5}$, penetration is complete for cracks heights greater than $\sim 1 \mathrm{~mm}$. However, penetration through $\mathrm{mm}$ scale cracks is small if the reaction probability is $\sim 10^{-4}$ or greater. For wall cavities, fiberglass insulation is an efficient particle filter, but particles would penetrate efficiently through uninsulated wall cavities or through insulated cavities with significant airflow bypass. The ozone reaction probability on fiberglass fibers was measured to be $10^{-7}$ for fibers previously exposed to high ozone levels and $6 \times 10^{-6}$ for unexposed fibers. Over this range, ozone penetration through fiberglass insulation would vary from $>90 \%$ to $\sim 10$ $40 \%$. Thus, under many conditions penetration is high; however, there are realistic circumstances in which building envelopes can provide substantial pollutant removal. Not enough is yet known about the detailed nature of infiltration leakage paths to reliably predict infiltration into real bui]dings.
\end{abstract}

Key words: exposure, infiltration, ozone, particles, penetration factor, reaction probability

\section{Introduction}

Because people spend a large proportion of their time in buildings, most exposure to air pollutants of outdoor origin occurs jndoors. However, the concentrations of air pollutants are not the same indoors as outdoors, even in the absence of indoor emissions. Pollutants may be lost or transformed as air enters buildings. Once indoors, pollutants may interact with indoor surfaces or undergo homogeneous transformations. Filters and other air cleaning devices may also reduce indoor poilutant levets.

In this paper, we consider the extent to which pollutants in outdoor air penetrate as the air infittrates into buildings through cracks and through wall cavities. A few comments are needed to establish the significance of this issue. All building envelopes leak. Many buildings, 
including most residences in the United States, are not equipped with mechanical ventilation systems. Therefore, when doors and windows are closed, as they often are during heating and cooling seasons, air exchange occurs mainly by uncontrolled air leakage across the building shell, known as infiltration. Exposure of building occupants to air pollutants of outdoor origin is affected by the extent to which those pollutants penetrate along with infiltrating air. Even in mechanically ventilated buildings, significant infiltration can occur and so pollutant penetration is relevant in these buildings too.

Pollutants of interest include particles and reactive gases. These may be urban air pollutants such as diesel soot or the constituents of photochemical smog. They may also be the products of fires or accidental releases from industrial facilities. Chemical and biological agents released by terrorists or through military action are of concern. Airborne pollen may cause respiratory allergies if it penetrates buildings after release from outdoor vegetation. The analyses in this paper are also pertinent to understanding exposure to bioaerosols associated with certain indoor moisture problems (Miller, 1992). Condensation and structural water leaks can lead to mold growth in wall cavities. The release of spores and microbial volatile organic compounds from molds can cause human exposure if the contaminants are subsequently transported into the occupied space.

These phenomena can be quantified in terms of penetration factors. Consider airflow into a building through some leakage path. Assume that pollutant removal from infiltrating air, which can occur by deposition or reaction on surfaces, is a steady, first-order loss process (i.e., the loss rate is proportional to the airborne concentration). Then, the average pollutant concentration in air as it exits is proportional to the concentration as it enters the leakage path. The ratio of these two concentrations is called the penetration factor, denoted $P$. Given a penetration factor, the rate of pollutant entry through a leakage path can be expressed as $P Q C_{o}$, where $Q$ is the volumetric airflow rate through that path and $C_{o}$ is the species concentration in outdoor air. (Strictly, this expression requires an adjustment for expansion or contraction if the air temperature changes along the flow path.) The penetration factor is a function of the pollutant species. It also depends on the geometry, surface materials, and pressure drop along the leakage path. When considering all the air that enters a building by infiltration, the average penetration factor for the entire envelope is the flow-weighted average of the penetration factors over all leakage paths.

Depending on the nature of pollutant-surface interactions, the penetration factor may vary with time or with environmental conditions such as temperature or relative humidity. Also, for certain pollutant-surface interactions, such as reversible sorption of volatile organic compounds, penetration may not be well described by a simple proportionality constant. These potentially important subtleties are not addressed in this paper.

A few published studies have evaluated penetration factors for airborne particles based mainly on experimental evidence (Thatcher and Layton, 1995; Özkaynak et al., 1996; Mosley et al., 2001). We know of no published work that experimentally investigates the penetration of reactive gases through leaks in building envelopes. However, Karlsson (1994) has briefly considered this phenomenon from a modeling perspective in the context of assessing exposure in buildings caused by accidental releases of toxic gases or attacks with chemical warfare agents. 
The objective of this paper is to explore airborne particle and reactive gas penetration through leakage paths in building envelopes. We seek quantitative estimates of penetration factors as well as an understanding of the variables that affect them. To achieve these goals, we adapt and apply mathematical models that are based on mechanistic knowledge of the governing processes. These models are used to analyze airflow through idealized representations of building leaks.

\section{Methods}

\subsection{Building Cracks}

We considered three configurations - straight-through, L-shaped, and double-bend that represent cracks commonly found in buildings (see Figure 1). The smallest dimension of the crack (known here as "crack height") is denoted $d$. The crack dimension parallel to airflow ("crack length") is denoted $z$. We assume that the crack geometry is uniform throughout the channel, that the inner surface is perfectly smooth, and that airflow through the crack is steady. We also assume that the extent of the crack in the third dimension ("crack width"), denoted $w$, is much larger than crack height, so that airflow can be reasonably modeled as two-dimensional.

\subsubsection{Airflow Characterization in Cracks}

The flow of air through a crack is driven by a small pressure difference ( $\triangle P$, typically less than $10 \mathrm{~Pa}$ ), which in turn may be induced by wind, indoor/outdoor temperature difference, or unbalanced fan-driven flow. The relationship between the airflow rate, $Q$, and pressure difference, $\Delta P$, is well approximated by this quadratic expression (Baker et al., 1987):

$$
\Delta P=\frac{12 \mu z}{w d^{3}} Q+\frac{\rho C}{2 d^{2} w^{2}} Q^{2}
$$

Here, $\mu$ is the dynamic viscosity of air and $\rho$ is the air density. The parameter $C$ is well approximated by $C=1.5+n_{b}$ where $n_{b}$ is the number of right-angle bends in the crack. Equation (1) reflects the key physical processes that control drag. When the flow channel is long and thin, viscous resistance dominates and the flow rate varies in direct proportion to $P$, as described by the first term on the right. For cracks that have a large height but are not long, inertial resistance associated with air density dominates, and the flow rate varies in proportion to $P^{0.5}$.

\subsubsection{Characterization of Building Cracks and their Dimensions}

The dimensions of air leakage cracks in buildings have not been well characterized. One investigation on air infiltration through gaps around closed windows suggested that crack heights were normally less than $2.5 \mathrm{~mm}$ (Thomas and Dick, 1953). Another study reported that crack heights of 0.5 to $7.5 \mathrm{~mm}$ represent the range commonly found in buildings (Hopkins and Hansford, 1974). 
Interest in ventilation and energy use has sputred studies of the leakage characteristics of buildings. These studjes have focused on quantifying the effective leakage area of whole buildings and of building components (Reinhold and Sonderegger, 1983). As is appropriate for air infiltration, this infomation is expressed in terms of an effective leakage area without specifying the crack dimensions. Unfortunately, pollutant penetration through cracks is very sensitive to the minimum crack dimension. The lack of detailed infomation on the distribution of crack sizes in buildings limits our ability to extend the modeling results presented in this paper to real buildings. Nevertheless, information on the overall air-leakage characteristics of singtefarnily residences can be used to constrain the domain of practical interest.

For example, assume that all cracks in a building have the same height, $d$, and length, $z$. Then, the total crack width $W$ can be estimated as the ratio of the leakagc area to crack height:

$$
W=\frac{\text { total leakage area } A}{\text { crack height } d}=\frac{1}{d} \frac{Q}{C_{D}(d) \sqrt{2 \Delta P / \rho}}
$$

where $C_{D}(d)$ refers to the discharge coeficient for crack height $d$. Equation (2) is based on a standard formula linking air infiltration to leakage area and pressure drop (ASHRAE, 1985). Figure 2 illustrates the dependence of $W$ on $d$ and $\Delta P$ for a postulated residential building with an. infiltration rate of $150 \mathrm{~m}^{3} \mathrm{~h}^{-1}$. For a medium-sized US house (volume $\sim 300 \mathrm{~m}^{3}$ ), the perimeter of the exterior walls and the doors and windows is on the order of hundreds of meters. Figure 2 shows that it is plaustible for ajr leaking into such a building to pass mostly through cracks whose beight is on the order of $\sim 0.5 \mathrm{~mm}$ or larger. However, the predominant flow must pass through cracks with $d \quad \sim 0.2 \mathrm{~mm}$. Otherwise, an unrealistically high value of tolal crack width would be required to yield the observed total building leakage.

In our analysis of pollutant penetration through cracks, the flow path length (z) was fixed at one of two values: 3 or $9 \mathrm{~cm}$. Various crack heights were considered $(d=0.05,0.10,0.25$, and $1.0 \mathrm{~mm}$ ). Although the smaller values are unlikcly to represent dominant flow paths, they were included to investigate how small a crack must be to prevent penetration of $\sim 0.1-1 \mu \mathrm{m}$ particles.

\subsubsection{Particle Penetration through Cracks}

Particle penetration through building cracks was estimated by considering the effects of three major particle deposition mechanisms: Brownian diffusion, gravitational settling, and impaction. Particles were assumed to be spherical with a density of $1 \mathrm{~g} \mathrm{~cm}^{-3}$ and with diameters ranging from 0.001 to $100 \mu \mathrm{m}$. The lower bound reflects the growing interest in the effects of ultrafine particles on human health (Oberdorster, et al, 1995). The largest particle sizes in this range are of concern for human exposure to norrespirable particles, such as large pollen grains.

We assumed thatairflow-within-a-crack is uniform-and-steady,and-that-the-particle concentration at the inlet is equal to that of the incoming airflow. The penetration factor due to gravitational settling alone $\left(P_{\mathrm{g}}\right)$ is computed from the results of trajectory analysis (Fuchs, 1964): 


$$
P_{g}=1-\frac{V_{s} z}{d U}
$$

where $V_{s}$ is the particle settling velocity and $U$ is the mean air speed in the crack. For the case of $V_{s} z \geq d U, P_{g}=0$ and there is no particle penetration.

Small particles may diffuse to the walls of a crack and adhere to the surfaces by means of van der Waals forces. The penetration factor through a crack considering Brownian diffusion alone $\left(P_{d}\right)$ is approximated from a result by De Marcus and Thomas (1952):

$$
P_{d}=0.915 \exp (-1.885 \phi)+0.0592 \exp (-22.3 \phi)+0.026 \exp (-152 \phi)+\ldots
$$

where $\phi$ is given by:

$$
\phi=\frac{4 D z}{d^{2} U}
$$

Here, $D$ is the particle diffusion coefficient. Equation (4) was derived by means of solving the equation of mass conservation, assuming well-developed parabolic flow with particle transport via advection and Brownian diffusion. The equation has been experimentally validated for particles smaller than $0.3 \mu \mathrm{m}$ (Thomas, 1955).

Particle deposition caused by impaction is a function of the Stokes number $(S t)$, which is the ratio of the particle stopping distance to the characteristic dimension associated with flow acceleration (Hinds, 1982). The greater the Stokes number (i.e., from increased particle inertia or a sharper bending of fluid streamlines), the higher the likelihood of particle impaction at crack bends. The system we are considering has similarities to particle-sampling impactors. Since impactor performance has been well characterized, we used results from rectangular impactor nozzles (Marple and Willeke, 1976) to estimate particle deposition at crack bends induced by inertial drift. The penetration factor associated with impaction, $P_{i}$, was taken as one minus the fractional loss caused by inertia. We found that impaction was not an important particle deposition mechanism for airflow through building cracks. Any particle with enough inertia to be lost by impaction was also likely to be lost by settling.

Based on the approximation that the deposition mechanisms operate independently, the total penetration factor was estimated as the product of the penetration factors for the three processes considered separately:

$$
P=P_{g} \times P_{d} \times P_{i}
$$

Alternative schemes for combining mechanisms to estimate overall particle penetration have been formulated (e.g., Chen and Yu, 1993). For the situation we are considering, where generally only one mechanism is important for a given particle size, differences among approaches are small. 


\subsubsection{Penetration of Reactive Gases through Cracks}

We consider gaseous pollutant loss on surfaces that occurs by a first-order, irreversible process. The species removal rate is parameterized in terms of a mass-transfer coefficient known as the deposition velocity, which is defined as the net pollutant flux to a surface divided by the freestream airborne concentration. In general, the deposition of reactive gases is governed by two mechanisms acting in series: (1) mass transport to surfaces, and (2) uptake by the surface. Following Cano-Ruiz et al. (1993), we model the overall mass transfer process as two resistances in series, such that the overall deposition velocity $\left(v_{o}\right)$ is expressed as follows:

$$
v_{o}=\left(\frac{1}{v_{s}}+\frac{1}{v_{t}}\right)^{-1}=\frac{v_{s} v_{t}}{v_{s}+v_{t}}
$$

Here, $v_{s}$ and $v_{f}$ refer to the species deposition velocity in the limit of control by surface uptake and control by gas-phase mass transport, respectively. From the kinetic theory of gases, the value of $v_{s}$ is estimated as

$$
v_{s}=\gamma \frac{\langle v\rangle}{4}
$$

where $\langle v\rangle$ is the Boltzmann velocity of the species. For ozone, for example, $\langle v\rangle$ is $\sim 360 \mathrm{~m} \mathrm{~s}^{-1}$ at $293 \mathrm{~K}$. The dimensionless parameter, $\gamma$, is the reaction probability, the ratio of the removal rate to the collision rate of the species on the surface. When $\gamma$ is sufficiently small (such that $v_{s} \ll<v_{t}$ ), the deposition velocity is controlled by the rate of surface uptake $\left(v_{o} \sim v_{s}\right)$. Table 1 summarizes the reaction probabilities for three gases - ozone, sarin and $\mathrm{SO}_{2}-$ on materials found in building envelopes, based on experimental data reported in the literature.

The transport-limited deposition velocity, $v_{t}$, is a function of the air flow field and the species molecular diffusivity. The overall deposition velocity $v_{o}$ approaches the transport-limited value $\left(v_{o} \sim v_{t}\right)$ when the surface resistance is small compared to the gas-phase mass-transfer resistance $\left(v_{s} \gg v_{t}\right)$. For specific flow conditions, we estimated the transported-limited deposition velocity by a two-step process. First, equations (4) and (5) were applied to determine the pollutant penetration factor, accounting for pollutant transport by means of molecular diffusion and advection, and assuming no surface resistance. Second, we used an idealized model to link the penetration factor to its deposition velocity. The model is derived by writing a species material balance over a differential slice normal to the direction of flow. We assume that flow is uniform and that the surface pollutant flux is equal to the product of the deposition velocity and the average species concentration in the slice. This expression is obtained for the penetration factor in the case of mass-transport-limited uptake:

$$
P_{d}=\exp \left(-\frac{2 v_{t} z}{U d}\right)
$$

Given $P_{d}$ from equation (4), equation (9) can be solved for $v_{t}$. This result is then combined with 
equations (7) and (8) to determine the overall species deposition velocity, including the combined effects of mass transfer and surface uptake. Finally, the overall penetration factor is computed using an equation that is analogous to equation (9):

$$
P=\exp \left(-\frac{2 v_{0} z}{U d}\right)
$$

For the examples considered in this paper, we selected ozone as a specific example of a reactive gas. The approach is applicable to other reactive gases.

\subsection{Wall Cavity}

\subsubsection{Wall Cavity Characterization}

Some air that leaks into buildings passes through wall cavities. In the U.S., most residential buildings are built with a wood frame. Wall cavities are bounded by the framing lumber and by the inner and outer wall materials. Typical dimensions for a single cavity are 10$15 \mathrm{~cm}$ (thick) $\times 35 \mathrm{~cm}$ (wide) $\times 2.5 \mathrm{~m}$ (high). For old houses in areas with mild climate, the wall cavities are commonly unfilled. Modern homes contain insulation materials in the wall cavity to save energy by reducing the rate of heat transfer through the building envelope. We considered three wall cavity configurations: uninsulated (Figure 3a), filled with insulation (Figure $3 \mathrm{~b}$ ), and insulated but with air leakage paths that bypass the insulation (Figure $3 \mathrm{c}$ ).

\subsubsection{Fiberglass Insulation in Wall Cavities}

Fiberglass is a widely used insulation material because it is inexpensive, easily installed, and versatile. Fiberglass insulation is commonly installed in the form of a fibrous blanket, cut to fit into the space between wall studs. Both the thickness and solidity of the fiberglass materials govern the insulation performance. In the US, commercial products are rated by an "R-value," which is a measure of thermal resistance, in units of $\mathrm{ft}^{2}-{ }^{\circ} \mathrm{F}-\mathrm{h} / \mathrm{BTU}$. Because it is fibrous, fiberglass insulation in wall cavities might serve as a pollutant filter. We used modeling tools to explore the penetration factor for particles and reactive gases through wall cavities filled with fiberglass insulation.

For the analyses reported here, we considered a fiberglass blanket of 8.9-cm thickness (R11). We considered flow path lengths through the fiberglass blanket of $L=8.9 \mathrm{~cm}$ (horizontal flow) and $L=2.3 \mathrm{~m}$ (vertical flow). (See Figure 3b.) Based on microscopíc examination of a sample purchased at a local hardware store, fibers were assumed to be uniform with a $10 \mu \mathrm{m}$ diameter. The solidity of the blanket $(\alpha)$ was estimated to be 0.003 , on the basis of a weight measurement and assuming that the fiber density was the same as bulk glass $\left(2.5-2.8 \mathrm{~g} \mathrm{~cm}^{-3}\right)$.

Air speed through the fiberglass blanket was computed by assuming a fixed pressure drop (4-10 Pa) across the flow path length and applying a theoretical expression linking air flow to pressure drop for fibrous filters (Hinds, 1982). At a pressure drop of $4 \mathrm{~Pa}$ across an $8.9-\mathrm{cm}$ 
thickness of R-11 fiberglass, we estimate an air speed of $2.4 \mathrm{~cm} \mathrm{~s}^{-1}$. The total infiltrating flow of $150 \mathrm{~m}^{3} \mathrm{~h}^{-1}$ into a typical residence would be generated by such a speed applied across a face area of $1.7 \mathrm{~m}^{2}$. Since the total exterior wall area of a residence is on the order of $100 \mathrm{~m}^{2}$, it is plausible that a significant fraction of infiltrating air passes follows pathway ( 1 ) as illustrated in Figure $3 \mathrm{~b}$. On the other hand, a pressure difference of $4 \mathrm{~Pa}$ applied across a $2.3-\mathrm{m}$ length of fiberglass blanket would only induce an air speed of $0.2 \mathrm{~cm} \mathrm{~s}^{-1}$. If air flowed in this manner through all exterior wall cavities, the total infiltration rate would only be on the order of $10 \mathrm{~m}^{3} \mathrm{~h}^{-}$ ${ }^{1}$, much smaller than observed infiltration rates. Therefore, we can exclude pathway (2) in Figure $3 \mathrm{~b}$ from further consideration of pollutant penetration.

\subsubsection{Particle Penetration Analysis}

Filtration theory was applied to calculate particle penetration through fiberglass insulation in wall cavities (Hinds, 1982). These deposition mechanisms were included in the analysis: interception, impaction, Brownian diffusion, and gravitational settling. Total single fiber efficiency $\left(\eta_{\Sigma}\right)$ was estimated by summing the collection efficiencies determined separately for each mechanism. Applying an approximation that all fibers have the same diameter $\left(d_{f}\right)$, the overall penetration fraction through the fiberglass blanket, $P_{f}$, is related to single-fiber efficiency by this expression:

$$
P_{f}=\exp \left(\frac{-4 \alpha \eta_{\Sigma} L}{\pi d_{f}}\right)
$$

\subsubsection{Ozone Penetration Analysis}

Ozone penetration through a fiberglass blanket is analyzed in an analogous manner to penetration through cracks. The transport-limited deposition velocity $\left(v_{t}\right)$ was estimated from particle filtration theory, accounting for only two transport mechanisms: advection and molecular diffusion. The transport-limited deposition velocity is related to the single-fiber efficiency by the following equation:

$$
v_{t}=\frac{\eta_{d}}{\pi} U_{o}
$$

where the single fiber efficiency due to diffusion alone is given by $\eta_{d}=2 P e^{-2 / 3}$ (Hinds, 1982), $P e$ is the Peclet number $\left(=U_{o} d_{f} / D\right)$, and $U_{o}$ is the freestream air speed approaching a fiber. The molecular diffusivity of ozone was taken to be $1.82 \times 10^{-5} \mathrm{~m}^{2} \mathrm{~s}^{-1}$.

The overall ozone deposition velocity to a single fiber was determined by equation (7). The surface reaction probability ( $\gamma$ ) was measured, as described below. Given $\gamma$, equation (8) was applied to determine $v_{s}$. The fractional ozone penetration through the fiberglass blanket was estimated by applying a variation of filtration theory: 


$$
P_{O 3}=\exp \left[-\frac{4 v_{0} \alpha L}{U_{o} d_{f}}\right]
$$

\section{RESULTS AND DISCUSSION}

\subsection{Building Cracks}

\subsubsection{Aiffiow Characteristics}

Air speeds through cracks were found to depend on crack beight (d), crack length (z), and pressure difference $(P)$, but to be independent of crack configuration. Selected results are presented in Table 2. For crack dimensions of practical interest, the flow is always laminar. For crack heights smaller than about $1 \mathrm{~mm}$ and crack lengths greater than about $3 \mathrm{~cm}$, the airflow is well described as laminar and fully developed. On the other hand, for cracks with a greater crack height or shorter flow length, the entrance length may approach a significant fraction of the flow length. In this case, the flow will be developing from a flat profile at the inlet toward the welldeveloped parabolic profile. Because developitg flow has a component of velocity that is notmal to and away from the crack surfaces, pollutant deposition by diffusion will be reduced somewhat in developing flow conditjons. This effect is not included in the analyses reported here.

\subsubsection{Particle Penetration}

Figure 4 shows predicted particle penetration factors $P$ as a function of particle diameter, crack height, and pressure difference for straight-through cracks with $z=3 \mathrm{~cm}$. The result suggests that accumulation-mode particles $(0.1-1 \mu \mathrm{m}$ diameter) have the highest penetration efficiency across the whole particle-size spectrum. This is expected, since larger and smaller particles are readily removed in cracks under the influences of gravitational settling and Brownian diffusion, respectively. As indicated in Figure 4, the penetration factor is predicted to be approximately one for accumulation mode particles when $d \quad 0.25 \mathrm{~mm}$.

For crack height $d=1 \mathrm{~mm}$, the particle fractional penetration is more than $90 \%$ for 0.01 to $7 \mu \mathrm{m}$ particles. When $d$ is smaller than $1 \mathrm{~mm}$, penetration varies significantly with crack height, even within this particle size range. At $d=0.25 \mathrm{~mm}$, for example, particles of diameter $0.1-1.0 \mu \mathrm{m}$ have penetration factors greater than 0.85 . At $d=0.1 \mathrm{~mm}$, only about half of $0.3-\mu \mathrm{m}$ particles penetrate. Particle penetration becomes negligible $(<2 \%$ ) for $d=0.05 \mathrm{~mm}$, regardless of particle size.

Figure 5 presents the_predicted_penetration factor as a function of crack length, 2 ( 3 and 9 $\mathrm{cm}$ ), for straight-through cracks with various crack heights at $\Delta \mathrm{P}=10 \mathrm{~Pa}$. Penetration is significantly reduced in the longer cracks for many particle sizes. For instance, the penetration factor of $0.03 \mu \mathrm{m}$ particles with $d=0.25 \mathrm{~mm}$ is about $70 \%$ at $z=3 \mathrm{~cm}$, but only about $10 \%$ at $z=$ $9 \mathrm{~cm}$. On the other hand, for $d=1 \mathrm{~mm}$, penetration is nearly complete $(P \quad 95 \%)$ for both crack lengths for particle diameters between 0.02 and $4 \mu \mathrm{m}$. 
We did not include entrance effects on particle penetration in our analyses. Although potentially significant, we believe that they are unlikely to have important effects on the results. For example, we did not include aspiration efficiency, which measures the particle concentration at the inlet of a flow channel divided by the average concentration in the approaching airflow. Aspiration efficiency is expected to be close to one for particles of small Stokes numbers, because they are able to follow air streamlines well. The Stokes numbers were small for most conditions considered in this study. For the largest particles, where the Stokes number may be large, predicted penetration is small because of gravitational settling within the crack.

Perhaps greater limitations of the analyses are related to the assumptions that crack geometry is regular and that crack surfaces are smooth. In real cracks, irregular geometry and surface roughness might increase particle deposition significantly. This issue is best explored by laboratory-based experimental studies.

\subsubsection{Overall Particle Penetration for a Building Shell with Variable Crack Heights}

In any real building, air leaks through many cracks with a distribution of dimensions. The overall particle penetration factor for the building is the flow-weighted average penetration for each crack. There are no data on the distribution of leak sizes within buildings. Nevertheless, some insight into the effects of distributed crack sizes can be gained by analyzing a hypothetical distribution. Here, we postulate that the crack size distribution has the following properties. The crack length is constant at $z=3 \mathrm{~cm}$. The crack height has a fixed upper and lower bound, $d_{\max }$ and $d_{\min }$, respectively. The fraction of crack area $(d \times w)$ between any two crack heights is proportional to the difference between those two crack heights. Mathematically, the total area of leaks can be related to such a crack-size distribution in this manner:

$$
A=\int_{d_{\min }}^{d_{\max }} d \times W(d) \times \mathrm{d}(d) \quad W(d) \propto \frac{1}{d}
$$

where $W(d)$ is the distribution function of crack widths. Although our postulated distribution might not be representative of crack-size distributions in real buildings, it is useful to illustrate the relative contributions of large and small cracks in influencing pollutant penetration.

The overall particle penetration factors for three pairs of $d_{\max }$ and $d_{\min }$ values are shown in Figure 6. A change in the lower bound of crack size $\left(d_{\min }\right)$ from 0.05 to $0.5 \mathrm{~mm}$ has an insignificant effect on the results. However, changing the upper bound from 1 to $2 \mathrm{~mm}$ changes the penetration factor for the particle sizes near the outer edges of the size distribution. These results indicate that overall penetration is influenced more by the largest cracks than by the smallest cracks in a building. The result is not surprising, since airflow rates increase strongly as crack height increases (Table 2 ).

\subsubsection{Ozone Penetration}

The predicted penetration factor for ozone as a function of reaction probability $(\gamma)$, crack 
height $(d)$, and pressure difference $(\Delta P)$ is illustrated in Figure $7 \mathrm{a}$ for $z=3 \mathrm{~cm}$ and in Figure $7 \mathrm{~b}$ for $z=9 \mathrm{~cm}$. Since the penetration factor decays exponentially with flow path lengths for fixed $\gamma$, much less ozone penetration is predicted for $z=9 \mathrm{~cm}$ than for $z=3 \mathrm{~cm}$.

Broadly, the relationship of ozone penetration and reaction probability can be divided into three regimes. For the following discussion, consider the example of a crack height of $d=1 \mathrm{~mm}$, a pressure difference of $P=10 \mathrm{~Pa}$, and a crack flow length of $z=3 \mathrm{~cm}$. For reaction probability $\gamma>\sim 10^{-3}$ ozone penetration is small and becomes independent of $\gamma$. In this region uptake is mass-transport limited: Reactions on the crack surfaces are sufficiently fast that the overall rate of uptake is governed by the rate at which ozone molecules reach the surface from the bulk air. For reaction probabilities in the range $\sim 10^{-5}<\gamma<\sim 10^{-3}$, ozone penetration varies with $\gamma$. In this part of the domain, surface uptake and gas-phase mass transfer both contribute significantly to uptake resistance. In the third regime, where $\gamma<\sim 10^{-5}$, ozone penetration becomes large. Uptake is governed entirely by surface kinetics. For all combinations of crack height, pressure difference, and flow length, the curves exhibit the same general shape. However, the values of $\gamma$ at which inflection points occur vary.

As shown in Table 1, the reaction probability of ozone is low on some building materials, such as glass and aluminum. On these surfaces, where typically $\gamma<\sim 10^{-6}$, ozone penetration is likely to be complete through cracks with height of $\sim 1 \mathrm{~mm}$ or larger, provided the crack flow length is less than approximately $9 \mathrm{~cm}$. Ozone reactivity is higher on other materials, such as concrete and brick. For these materials, where $\gamma \sim(0.4-2) \times 10^{-4}$, significant ozone loss may occur by reaction on surfaces through cracks with heights of as much as 1-2 mm.

\subsection{Wall Cavity}

\subsubsection{Particle Penetration}

\section{(1) Uninsulated wall cavity}

In a typical single-family residence, the total air volume in the exterior wall cavities would be on the order of $10 \mathrm{~m}^{3}$. If a significant fraction of infiltrating air passes through wall cavities, then the characteristic residence time of air in the cavity would be of the order of 5-10 minutes. Applying results from studies of deposition onto room surfaces (Nazaroff et al., 1993; Lai and Nazaroff, 2000), particle loss during this short residence time is expected to be insignificant, except for the smallest ultrafine and the largest coarse particles. These particles are likely to be lost during airflow through cracks into or out of the wall cavity. Therefore, it is unlikely that particle loss in an uninsulated wall cavity is important in understanding particle penetration.

\section{(2) Wall cavity insulated with a fiberglass blanket}

When fiberglass insulation is well installed, without airflow bypass, infiltrating air that enters a wall cavity must pass through the fibrous materials. Using particle filtration theory, the 
predicted particle penetration factor was found to be zero for flow path (1) in Figure $3 \mathrm{~b}$. This result applies for all particle sizes, regardless of pressure difference. Fiberglass insulation acts as an effective particle filter to the extent that infiltrating air passes through it. This result is consistent with anecdotal observations of soot-stained fiberglass insulation in the walls of residences undergoing retrofit.

However, airflow paths through a wall cavity may bypass the insulation, as depicted in Figure $3 \mathrm{c}$. On the basis of our analysis of particle penetration through idealized cracks, we infer that particle penetration through an insulated wall cavity would be large if the air flows through bypass channels with minimum dimensions larger than a few $\mathrm{mm}$.

\subsubsection{Ozone Penetration}

To evaluate the fractional ozone penetration through fiberglass insulation, we measured the reaction probability $(\gamma)$ for ozone on fiberglass fibers. We employed the apparatus that was used by Morrison and Nazaroff (2000) to measure ozone uptake on carpet fibers. The reaction probability for ozone on fiberglass was determined to be $6 \times 10^{-6}$ for freshly exposed fibers. The reaction probability dropped to about $10^{-7}$ after exposure to an elevated ozone level (1000 ppb) for 1 day. Over this range of values for $\gamma$, surface uptake kinetics represent the rate-limiting step for ozone deposition in a fiberglass blanket. Figure 8 shows the predicted ozone penetration according to equation (12) for airflow through a fiberglass blanket along pathway (1) in Figure 3b. For $\gamma \sim 10^{-7}$, ozone penetration is predicted to exceed $95 \%$. On the other hand, for $\gamma \sim 6 \times$ $10^{-6}$, ozone penetration is much smaller, in the range $10-40 \%$. These results indicate that scavenging by fiberglass insulation may affect ozone penetration into modern houses.

\section{Conclusions}

We have applied tools from engineering analysis, incorporating data on building leakage characteristics and information on pollutant-surface interactions, to explore the penetration of pollutants from outdoors into buildings. For relatively large cracks (height $>\sim 1 \mathrm{~mm}$ ), particle penetration is complete, except for the largest (diameter $>\sim 10 \mu \mathrm{m}$ ) and smallest (diameter $<\sim$ $0.01 \mu \mathrm{m})$ particles. Gas penetration is also complete for large cracks unless the pollutant-surface reaction probability $(\gamma)$ exceeds $\sim 10^{-5}$. For air that flows through fiberglass insulation in a wall cavity, particle penetration drops to zero and gaseous pollutant penetration is also less than one when the pollutant-surface reaction probability exceeds $\sim 10^{-7}$.

Existing information about the leakage characteristics of buildings provides important clues, but is not yet sufficient to reliably predict pollutant penetration into real buildings from models. Data are required on two important issues. First, how is air leakage into buildings distributed with respect to crack dimensions? A small number of large cracks would produce high penetration factors. The same total leakage distributed among a large number of small cracks could produce much lower penetration factors. Second, to what extent does the air that flows into buildings pass through insulation rather than around it? Pollutant penetration into buildings depends substantially on whether or not a large portion of the airflow passes through fiberglass insulation blankets. 
We believe that the modeling calculations presented here provide important insight into the expected values of pollutant penetration and the factors that affect them. Further progress will require experimental studies conducted on several scales, including penetration through single cracks, penetration through building components such as windows, and penetration across entire building shells. Advances in this area of study hold the promise of improving our ability to predict human exposure to pollutants of outdoor origin. Technological advances aimed at passively reducing pollutant penetration into buildings as a means of reducing human exposure also appear feasible.

\section{Acknowledgments}

The work was support by the Office of Research and Development, Office of Nonproliferation and National Security, U.S. Department of Energy under Contract No. DEAC03-76SF00098. Additional support was provided by the UC Toxic Substances Research and Training Program.

\section{References}

ASHRAE, 1985. ASHRAE Handbook: 1985 Fundamentals. American Society of Heating, Refrigerating, and Air-Conditioning Engineers, Atlanta, Chapter 22.

Baker, P.H., Sharples, S., Ward, I.C., 1987. Air-flow through cracks. Building and Environment 22, 293-304.

Cano-Ruiz, J.A., Kong, D., Balas, R.B., Nazaroff, W.W., 1993. Removal of reactive gases at indoor surfaces: Combining mass transport and surface kinetics. Atmospheric Environment 27A, 2039-2050.

Chen, Y.K., Yu, C.P., 1993. Particle deposition from duct flows by combined mechanisms. Aerosol Science and Technology 19, 389-395.

Cox, R.A., Penkett, S.A., 1972. Effect of relative humidity on disappearance of ozone and sulfur dioxide in contained systems. Atmospheric Environment 6, 365-368.

De Marcus, W., Thomas, J.W., 1952. Theory of a diffusion battery. U. S. Atomic Energy Commission, Oak Ridge National Laboratory, Oak Ridge, Tennessee.

Fuchs, C.N., 1964. The Mechanics of Aerosols. Pergamon Press, Oxford.

Hinds, W.C., 1982. Aerosol Technology. Wiley, New York.

Hopkins, L.P., Hansford, B., 1974. Air flow through cracks. Building Services Engineer 42, 123131.

Karlsson, E., 1994. Indoor deposition reducing the effect of toxic gas clouds in ordinary buildings. Journal of Hazardous Materials 38, 313-327.

Karlsson, E., Huber, U., 1996. Influence of desorption on the indoor concentration of toxic gases. Journal of Hazardous Materials 49, 15-27.

Lai, A.C.K., Nazaroff, W.W., 2000. Modeling indoor particle deposition from turbulent flow onto smooth surfaces. Journal of Aerosol Science 31, 463-476.

Marple, V.A., Willeke, K., 1976. Impactor design. Atmospheric Environment 10, 891-896.

Miller, J.D., 1992. Fungi as contaminants in indoor air. Atmospheric Environment 26, 2163 2172.

Morrison, G.C., Nazaroff, W.W., Cano-Ruiz, J.A., Hodgson, A.T., Modera, M.P., 1998. Indoor 
air quality impacts of ventilation ducts: Ozone removal and emissions of volatile organic compounds. Journal of the Air and Waste Management Association 48, 941-952.

Morrison, G.C., Nazaroff, W.W., 2000. The rate of ozone uptake on carpets: Experimental studies. Environmental Science \& Technology 34, 4963-4968.

Mosley, R.B., Greenwell, D.J., Sparks, L.E., Guo, Z., Tucker, W.G., Fortmann, R., Whitfield, C., 2001. Penetration of ambient fine particles into the indoor environment, Aerosol Science and Technology 34, 127-136.

Mueller, F.X., Loeb, L., Mapes, W.H., 1973. Decomposition rates of ozone in living areas. Environmental Science \& Technology 7, 342-346.

Nazaroff, W.W., Gadgil, A.J., Weschler, C.J., 1993. Critique of the use of deposition velocity in modeling indoor air quality. In Nagda, N.L. (ed.), Modeling of Indoor Air Quality and Exposure, ASTM STP 1205, American Society for Testing and Materials, Philadelphia, pp. 81-104.

Oberdörster, G., Gelein, R.M., Ferin, J., Weiss, B., 1995. Association of particulate air pollution and acute mortality: Involvement of ultrafine particles. Inhalation Toxicology 7, 111-124.

Özkaynak, H., Xue, J., Spengler, J., Wallace, L., Pellizzari, E., Jenkins, P., 1996. Personal exposure to airborne particles and metals: Results from the particle TEAM study in Riverside, California, Journal of Exposure Analysis and Environmental Epidemiology 6, 5778.

Reinhold, C., Sonderegger, R., 1983. Component leakage areas in residential buildings. Report LBL-16221, Lawrence Berkeley Laboratory, Berkeley, California.

Reiss, R., Ryan, P.B., Koutrakis, P., 1994. Modeling ozone deposition onto indoor residential surfaces. Environmental Science \& Technology 28, 504-513.

Sabersky, R.H., Sinema, D.A., Shair, F.H., 1973. Concentrations, decay rates, and removal of ozone and their relation to establishing clean indoor air. Environmental Science \& Technology 7, 347-353.

Simmons, A., Colbeck, I, 1990. Resistance of various building materials to ozone deposition Environmental Technology 11, 973-978.

Spedding, D.J., 1972. Sorption of sulphur dioxide by indoor surfaces. IV. Flooring materials. Journal of Applied Chemistry and Biotechnology 22, 1-8.

Thatcher, T.L., Layton, D.W., 1995. Deposition, resuspension, and penetration of particles within a residence. Atmospheric Environment 29, 1487-1497.

Thomas, D.A., Dick, B.A., 1953. Air infiltration through gaps around windows. Journal of the Institution of Heating and Ventilating Engineers 21, 85-97.

Thomas, J.W., 1955. The diffusion battery method for aerosol particle size determination. Journal of Colloid Science 10, 246-255. 


\section{FIGURE CAPTIONS}

Figure 1 Configuration of three types of idealized cracks through building envelopes.

Figure 2 Total crack width versus crack height (assumed uniform) necessary to support an infiltration rate of $150 \mathrm{~m}^{3} \mathrm{~h}^{-1}$, which is typical for a single-family residence.

Figure 3 Schematic of airflow paths through wall cavities in wood-frame construction. (a) Uninsulated wall cavity; (b) Wall cavity filled with fiberglass insulation; and (c) Fiberglass-insulated wall cavity with airflow bypass.

Figure 4 Particle penetration factor as a function of particle diameter, crack height, and pressure difference for a straight-through crack with flow length $z=3 \mathrm{~cm}$.

Figure 5 Particle penetration factor as a function of particle diameter, crack height, and flow length at a fixed pressure drop of $\Delta P=10 \mathrm{~Pa}$.

Figure 6 Overall particle penetration factor for a building with crack area distributed uniformly with respect to crack height. Results are presented for three different ranges of crack sizes.

Figure 7 Ozone penetration factor through a single crack as a function of reaction probability, crack height, and pressure difference for two flow path lengths (a) $z=$ $3 \mathrm{~cm}$ and (b) $z=9 \mathrm{~cm}$.

Figure 8 Ozone penetration factor for airflow through a fiberglass blanket as a function of ozone-fiber reaction probability. 

Table 1. Reaction probability $(\gamma)$ for sarin, $\mathrm{SO}_{2}$, and ozone on selected building materials.

\begin{tabular}{|c|c|c|c|}
\hline Species & Material & $\gamma^{a}$ & Reference \\
\hline Sarin & $\begin{array}{l}\text { Silanized glass, } 0-60 \% \mathrm{RH} \\
\text { Plastic coated wallpaper } \\
\text { Rough spruce, } 50-60 \% \mathrm{RH} \\
\text { Chalking paint on concrete }\end{array}$ & $\begin{array}{l}1.6 \times 10^{-8} \\
2.1 \times 10^{-8} \\
1.9 \times 10^{-8} \\
5.1 \times 10^{-7}\end{array}$ & Karlsson and Huber, $1996^{\mathrm{b}}$ \\
\hline $\mathrm{SO}_{2}$ & $\begin{array}{l}\text { Gloss paint, } 32 \% \mathrm{RH} \\
84 \% \mathrm{RH} \\
\text { Aluminum, } 78 \% \mathrm{RH}\end{array}$ & $\begin{array}{l}1.5 \times 10^{-7} \\
5.0 \times 10^{-6} \\
5.7 \times 10^{-6}\end{array}$ & Cox and Penkett, $1972^{\circ}$ \\
\hline & $\begin{array}{l}\text { Softwood } \\
\text { Hardwood, } 65 \% \mathrm{RH} \\
\text { PVC wall covering, } 60 \% \mathrm{RH}\end{array}$ & $\begin{array}{l}3.1 \times 10^{-4} \\
6.2 \times 10^{-4} \\
3.9 \times 10^{-5}\end{array}$ & Spedding, $1972^{d}$ \\
\hline Ozone & $\begin{array}{l}\text { Dirty glass } \\
\text { Clean glass } \\
\text { Bricks (new and old) } \\
\text { Outdoor concrete } \\
\text { Concrete slab }\end{array}$ & $\begin{array}{l}2.9 \times 10^{-6} \\
5.5 \times 10^{-6} \\
2.2 \times 10^{-4} \\
4.4 \times 10^{-5} \\
7.9 \times 10^{-5}\end{array}$ & Simmons and Colbeck, $1990^{\mathrm{e}}$ \\
\hline & $\begin{array}{l}\text { Plywood }{ }^{f} \\
\text { Plate glass } \\
\text { Aluminum }^{f}\end{array}$ & $\begin{array}{l}4.7 \times 10^{-6}-5.8 \times 10^{-7} \\
1.1 \times 10^{-7}-5.5 \times 10^{-8} \\
1.1 \times 10^{-6}-5.5 \times 10^{-8}\end{array}$ & Sabersky et al., $1973^{\circ}$ \\
\hline & $\begin{array}{c}\text { Aluminum, } 5 \% \mathrm{RH} \\
40-50 \% \mathrm{RH}\end{array}$ & $\begin{array}{c}4.9 \times 10^{-8} \\
7.0 \times 10^{-7}-1.3 \times 10^{-7}\end{array}$ & Mueller et al., $1973^{\circ}$ \\
\hline & $\begin{array}{l}\text { Aluminum, } 32 \% \mathrm{RH} \\
83 \% \mathrm{RH}\end{array}$ & $\begin{array}{l}7.7 \times 10^{-8} \\
2.3 \times 10^{-7}\end{array}$ & Cox and Penkett, $1972^{\circ}$ \\
\hline & $\begin{array}{l}\text { Latex paint, }<10 \% \mathrm{RH}^{\mathrm{f}} \\
\quad \sim 80 \% \mathrm{RH}^{\mathrm{f}} \\
\text { Glass } \\
\text { Vinyl wallpaper } \\
\text { Paper wallpaper }\end{array}$ & $\begin{array}{c}2 \times 10^{-6}-7 \times 10^{-7} \\
2 \times 10^{-5}-1 \times 10^{-6} \\
<1 \times 10^{-6} \\
5 \times 10^{-6} \\
1 \times 10^{-6}\end{array}$ & Reiss et al., 1994 \\
\hline & Galvanized sheet steel & $1.1 \times 10^{-6}$ & Morrison et al., 1998 \\
\hline
\end{tabular}

${ }^{a}$ Italicized values were inferred from the reference; others are directly quoted.

${ }^{b}$ The $\gamma$ values were estimated from reported first-order decay rate and surface/volume ratios.

${ }^{\mathrm{c}}$ Both first-order decay constant and deposition velocity were reported.

${ }^{\mathrm{d}}$ Estimated from deposition velocity reported in the reference.

${ }^{\mathrm{C}}$ As cited by Cano-Ruiz et al., 1993.

${ }^{f}$ Range of values reflect the decrease in uptake with prolonged ozone exposure. 

Table 2. Airflow parameters as a function of crack height for selected conditions. ${ }^{\text {a }}$

\begin{tabular}{cccc}
\hline Crack height, mm & Air speed, $\mathrm{cm} \mathrm{s}^{-1}$ & Reynolds number $^{\mathrm{b}}$ & Entrance length $^{\mathrm{c}}$ \\
\hline 0.05 & 0.4 & 0.01 & $1.1 \times 10^{-6}$ \\
0.10 & 1.4 & 0.08 & $1.6 \times 10^{-5}$ \\
0.25 & 9.6 & 1.3 & $6.7 \times 10^{-4}$ \\
1.00 & 131 & 73 & $1.5 \times 10^{-1}$ \\
\hline
\end{tabular}

${ }^{2}$ Conditions: flow path length $(z)=3 \mathrm{~cm}$ and pressure drop $(P)=10 \mathrm{~Pa}$.

${ }^{\mathrm{b}}$ Reynolds number, $\mathrm{Re}=U d / v$, where $U$ is the air speed and $v$ is the kinematic viscosity of air.

${ }^{c}$ Dimensionless entrance length, $x_{d} / z$, estimated as $0.06 d \operatorname{Re}=0.06 U d^{2} / v$. 



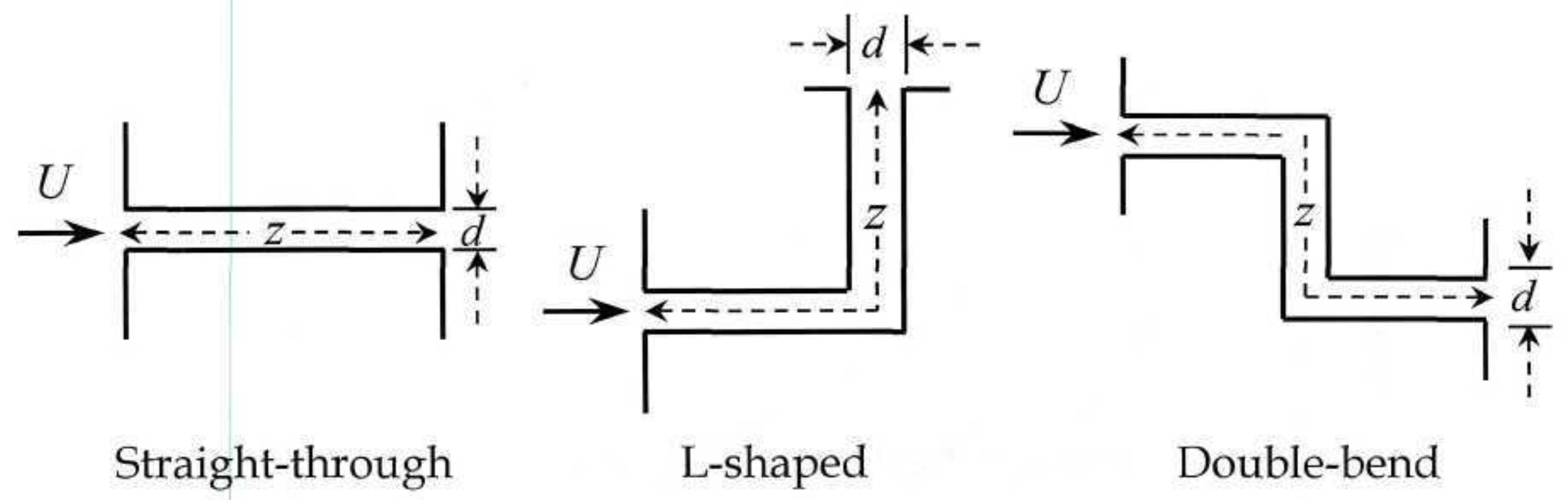

Figure 1 Configuration of three types of idealized cracks through building envelopes. 


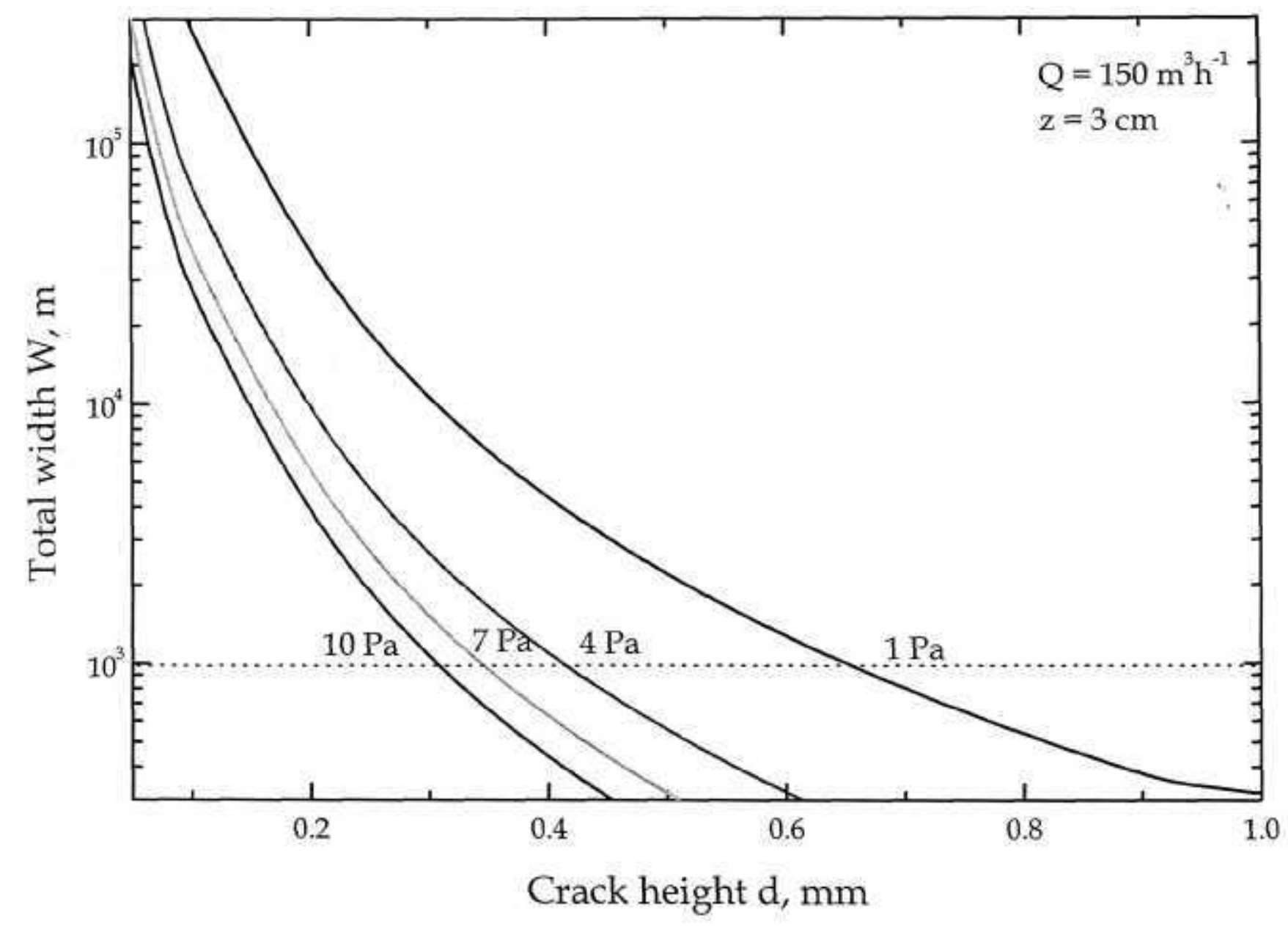

Figure 2 Total crack width versus crack height (assumed uniform) necessary to support an infiltration rate of $150 \mathrm{~m}^{3} \mathrm{~h}^{-1}$, which is typical for a single-family residence. 


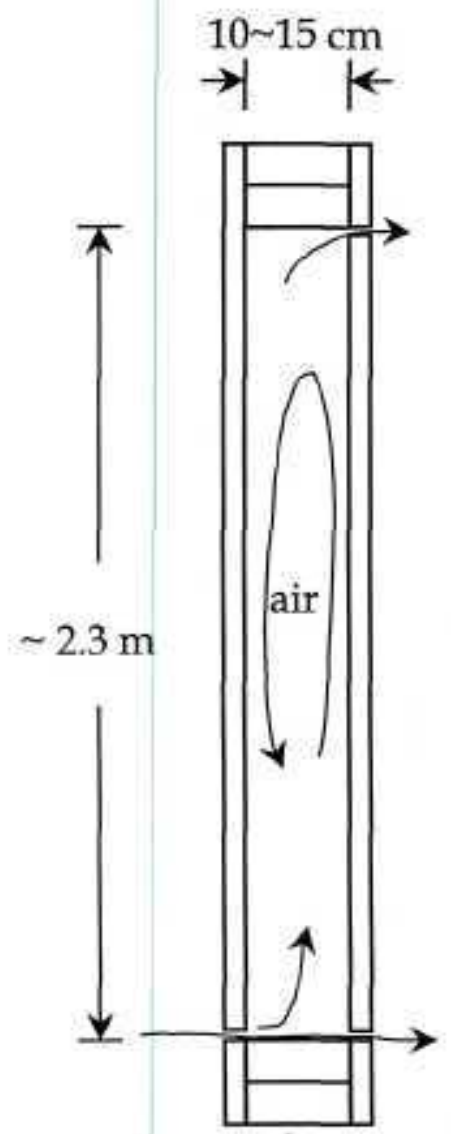

(a)

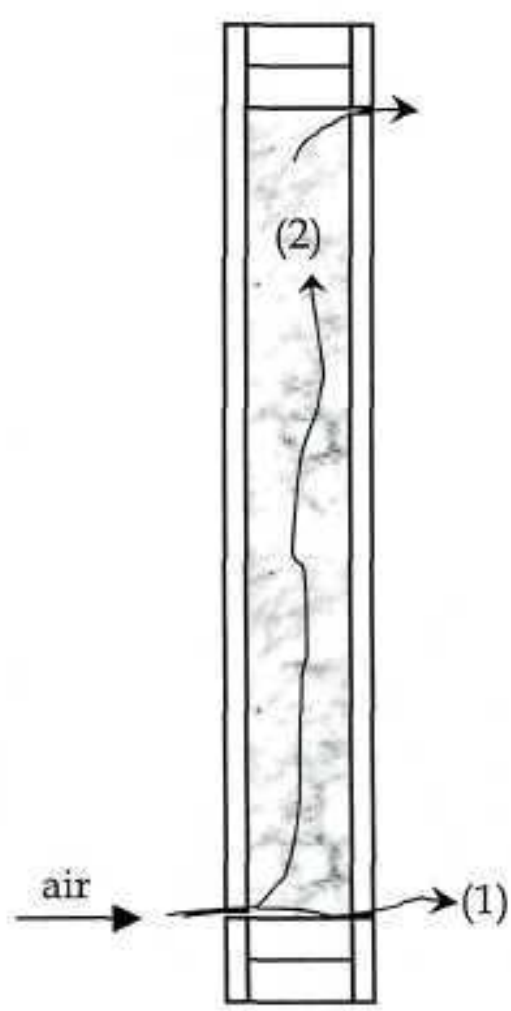

(b)

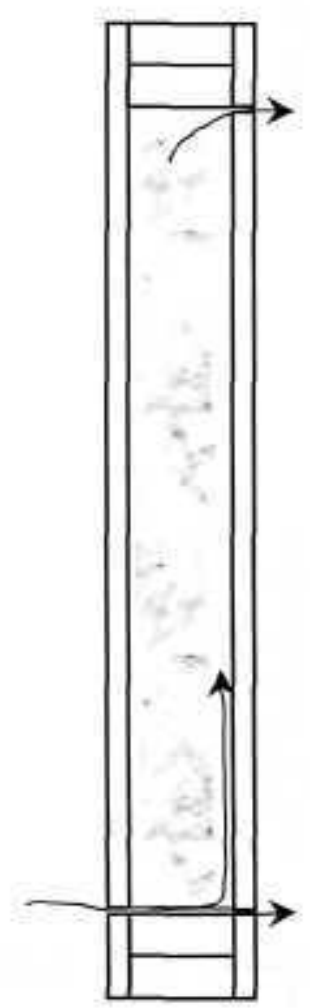

(c)

Figure 3 Schematic of airflow paths through wall cavities in wood-frame construction. (a) Uninsulated wall cavity; (b)Wall cavity filled with fiberglass insulation; and (c) Fiberglass-insulated wall cavity with airflow bypass. 


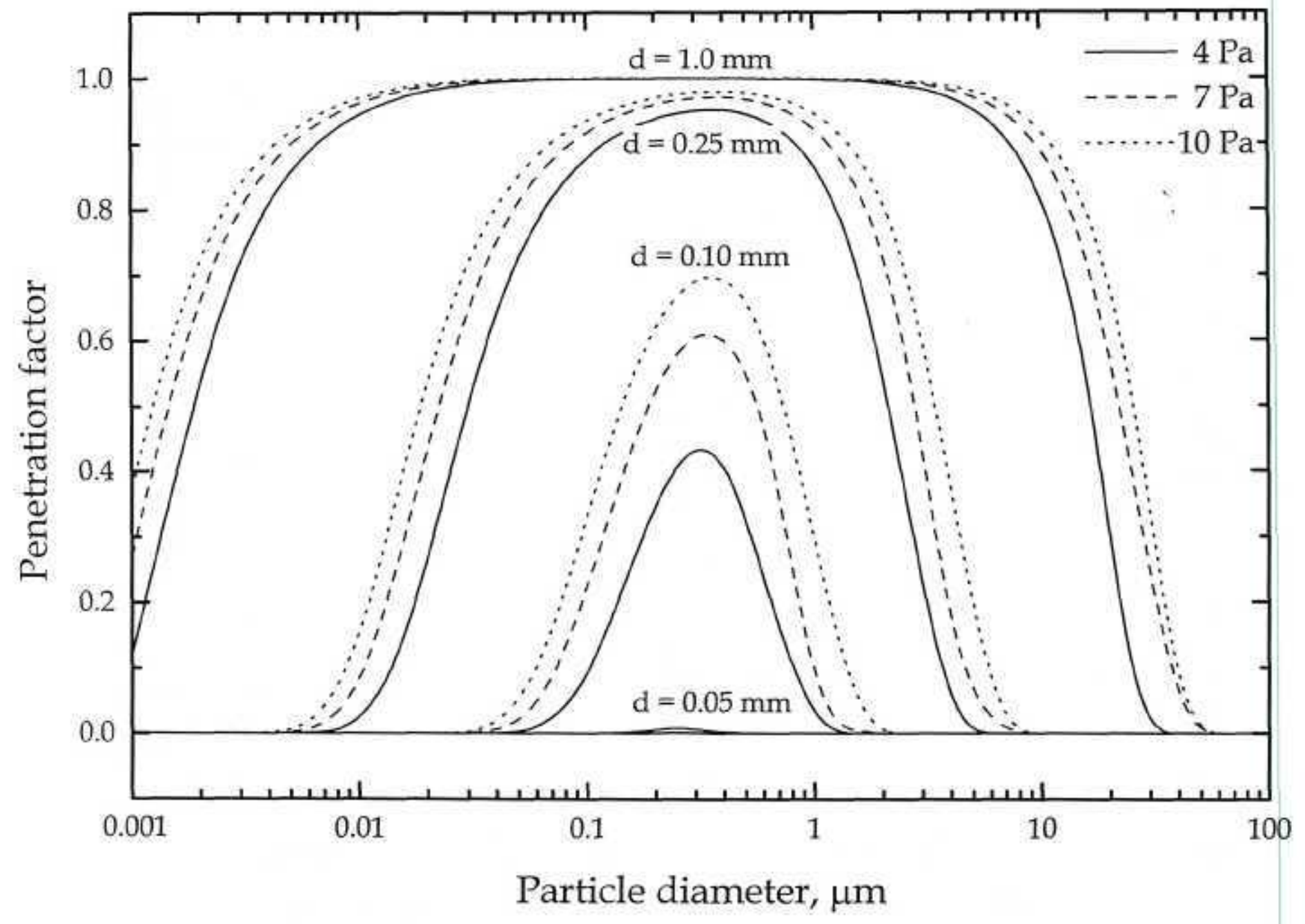

Figure 4 Particle penetration factor as a function of particle diameter, crack height, and pressure difference for a straight-through crack with flow length $\mathrm{z}=3 \mathrm{~cm}$. 


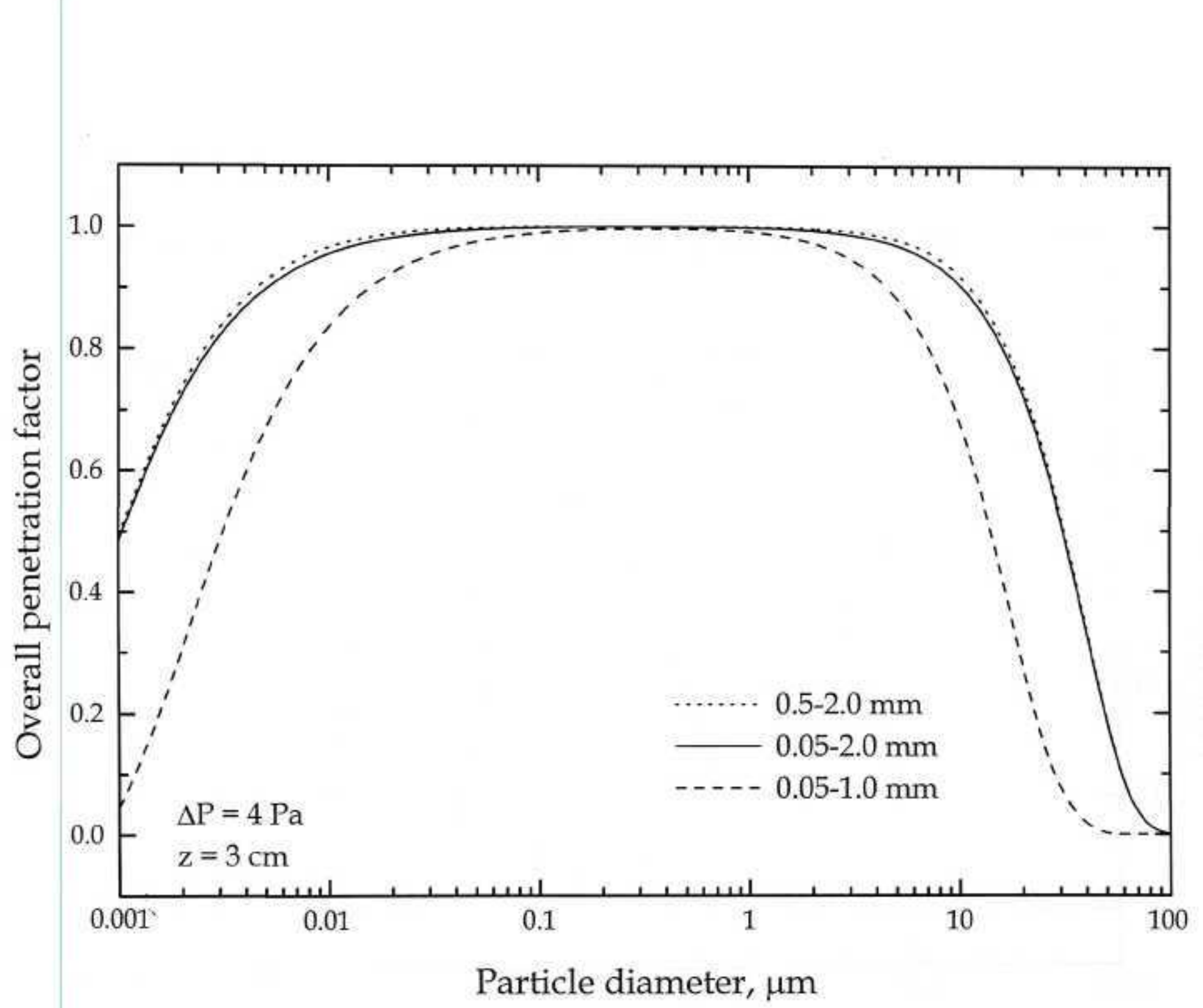

Figure 6 Overall particle penetration factor for a building with crack area distributed uniformly with respect to crack height. Results are presented for three different ranges of crack sizes. 


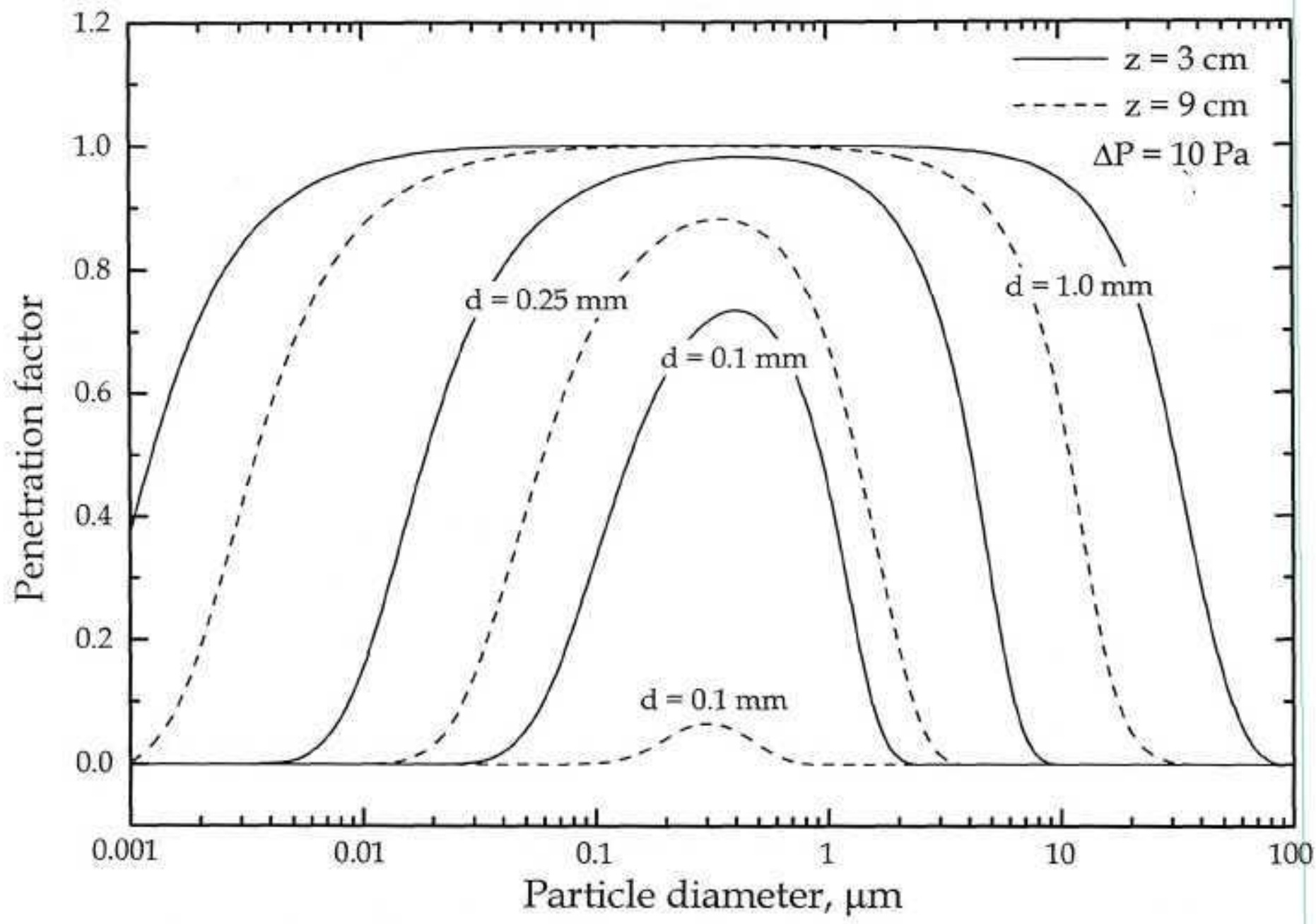

Figure 5 Particle penetration factor as a function of particle diameter, crack height, and flow length at a fixed pressure drop of $\Delta \mathrm{P}=10 \mathrm{~Pa}$. 

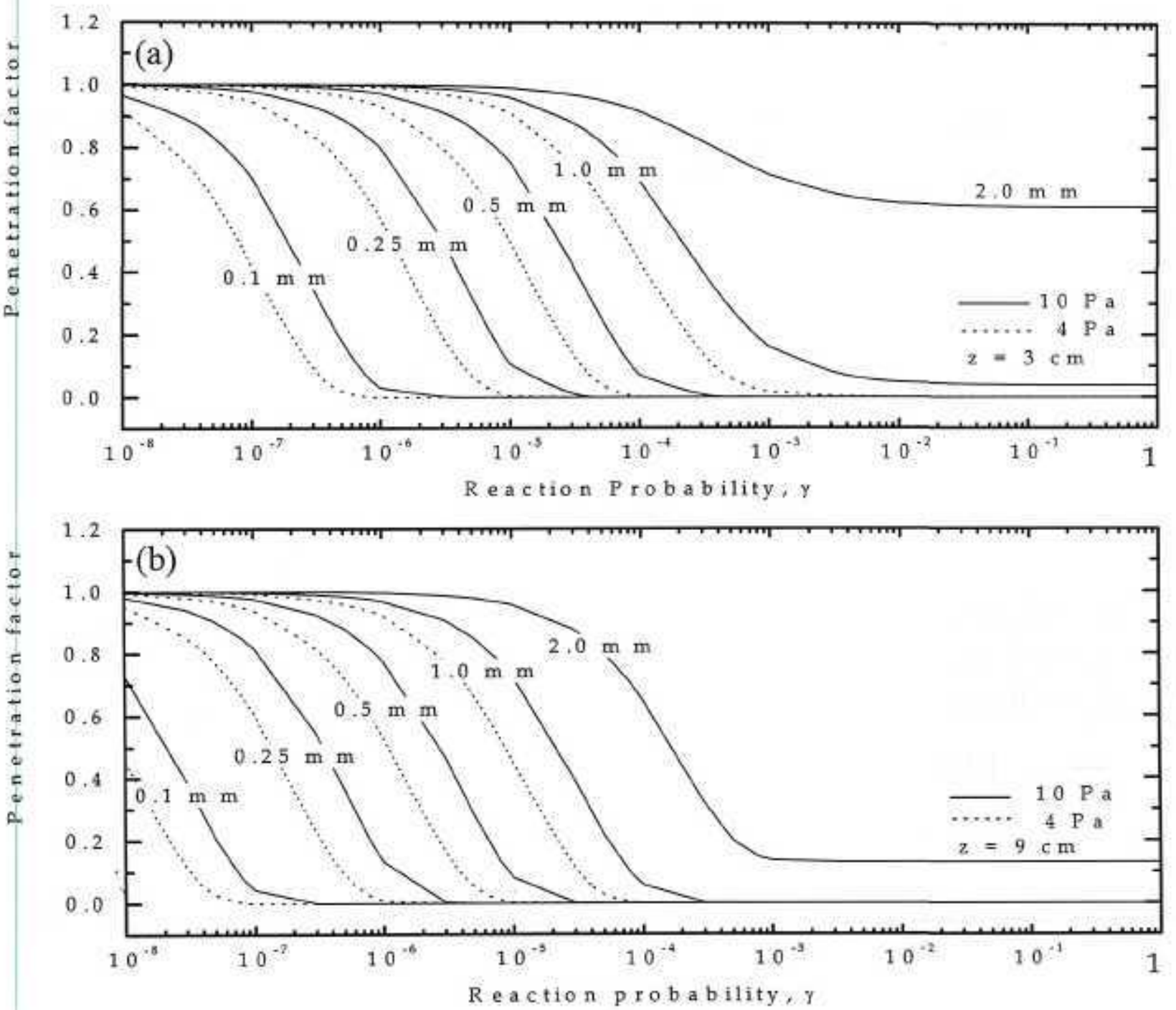

Figure 7 Ozone penetration factor through a single crack as a function of reaction probability, crack height, and pressure difference for two flow path lengths (a) $z=3 \mathrm{~cm}$ and (b) $\mathrm{z}=9 \mathrm{~cm}$. 


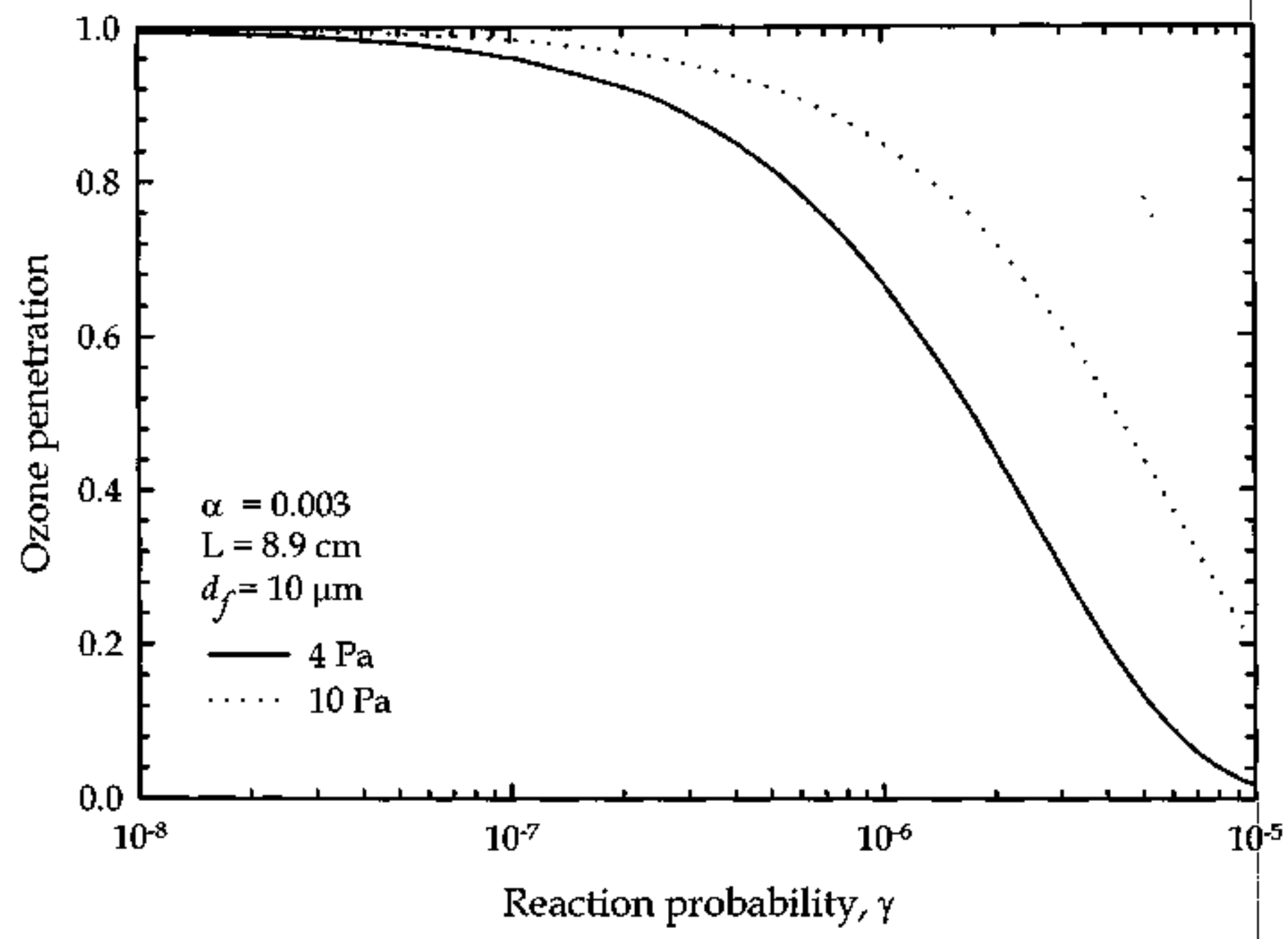

Figure 8 Ozone penetration factor for airflow through a fiberglass blanket as a function of ozone-fiber reaction probability. 